\title{
THE NATIONAL SPHERICAL TOKAMAK EXPERIMENT \\ AT THE PRINCETON PLASMA PHYSICS LABORATORY
}

December 1995

\section{DISCLAIMER}

This report was prepared as an account of work sponsored by an agency of the United States Government. Neither the United States Government nor any agency thereof, nor any of their employees, makes any warranty, express or implied, or assumes any legal liability or responsibility for the accuracy, completeness, or usefulness of any information, apparatus, product, or process disclosed, or represents that its use would not infringe privately owned rights. Reference herein to any specific commercial product, process, or service by trade name, trademark, manufacturer, or otherwise does not necessarily constitute or imply its endorsement, recommendation, or favoring by the United States Government or any agency thereof. The views and opinions of authors expressed herein do not necessarily state or reflect those of the United States Government or any agency thereof.

\section{U.S. DEPARTMENT OF ENERGY ARGONNE, ILLINOIS 60439}

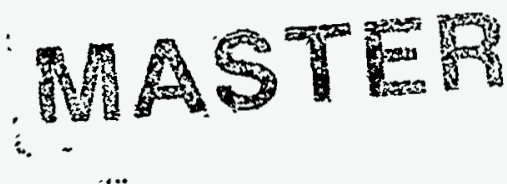




\section{THE NATIONAL SPHERICAL TOKAMAK EXPERIMENT AT THE PRINCETON PLASMA PHYSICS LABORATORY}

\subsection{PURPOSE AND NEED FOR THE PROPOSED ACTION}

If the United States is to meet the energy needs of the future, it is essential that new technologies emerge to compensate for dwindling supplies of fossil fuels and the eventual depletion of fissionable uranium used in present-day nuclear reactors. Fusion energy has the potential to become a major source of energy for the future. Power from fusion would provide a substantially reduced environmental impact as compared with other forms of energy generation. The purpose of the National Spherical Tokamak Experiment (NSTX) is to support fusion physics development and technology, by providing an experimental device to investigate the confinement and performance of plasmas produced in a spherical shaped tokamak. This concept has the potential to simplify the application of the tokamak approach for power production. A tokamak is a toroidal (doughnut-shaped) device for producing controlled nuclear fusion. The fusion reactions that would occur in the NSTX tokamak involve various combinations of hydrogen $(\mathrm{H})$ and deuterium (D) (i.e., H-D and D-D reactions). The fuel must be heated to high temperatures for the reactions to take place. The fuel is suspended and contained in the tokamak in a magnetic field and is heated by electrical current, neutral beam injection and radio-frequency (RF) waves.

The proposed action would take place within the C-Stellarator (CS) building at the Princeton Plasma Physics Laboratory (PPPL). The building is located on "C-Site" at the James Forrestal Campus of Princeton University in Plainsboro Township, Middlesex County, New Jersey, and is operated under contract with the United States Department of Energy (DOE).

\subsection{Purpose}

The purpose of the proposed NSTX is to investigate the physics of spherical tokamak plasmas at dimensions and performance levels larger than those previously studied on smaller scale devices. Results from these small machines indicate that a tokamak having low aspect ratio (i.e., ratio of major plasma radius, $R$, to minor plasma radius, a; see Figure 2-1) may be potentially attractive as a volume neutron source or as an advanced fuel cycle (i.e., non-tritium fueled) fusion reactor, as well as a deuterium-tritium (D-T) fusion reactor. In addition, because low aspect ratio tokamaks can be made smaller than high aspect ratio tokamaks (e.g., such as the existing Tokamak Fusion Test Reactor, TFTR, or the proposed International Thermonuclear Experimental Reactor, ITER) and operate at high plasma pressures, spherical tokamaks may ultimately have cost-ofelectricity advantages over conventional tokamak machines. It is desirable to construct a modest experiment to serve as a logical step beyond the first generation of spherical tokamaks and as a predecessor to a full scale volume neutron source or spherical tokamak reactor. 


\subsection{Need}

The current state of fusion technology lacks information on the physics of low aspect ratio plasmas having reactor relevant plasma currents (1 MegaAmpere [MA]), high plasma temperatures, and long $(5 \mathrm{sec})$ pulse lengths. The NSTX would be designed to acquire data in this area, which would contribute to the development of fusion reactors as a potential energy source.

\subsection{DESCRIPTION OF THE PROPOSED ACTION AND ALTERNATIVE}

\subsection{NSTX Project}

The proposed action consists of the construction and operation of the National Spherical Tokamak Experiment (NSTX) within the existing C-Stellarator (CS) Building at C-Site of PPPL. The NSTX would make use of existing parts, specifically, the upper and lower domes and the poloidal field coils of the existing non-operational S-1 spheromak. It would be located on the platform presently used for the non-operational Princeton Large Torus (PLT); thus, dismantlement and removal of the PLT device would be required. All existing parts that would be used to assemble the NSTX, as well as the waste resulting from dismantling and removal of the PLT, would be nonradioactive.

\subsubsection{NSTX Construction}

Location of the proposed NSTX device in the existing PLT test cell area on the PLT support platform would require dismantling and removal of the PLT device. A recent radiation survey conducted of the PLT indicates no detectable gamma or beta radiation (Kugel, 1995a). The PLT equipment removed would either be stored onsite at a different location, recycled offsite as scrap metal, or disposed offsite. The PLT toroidal field (TF) coils (total weight of 102 tons of copper) would be stored onsite for future use on other projects. The stainless steel machine supports (total weight of 9 tons) would also be stored onsite for future use. The disposable items, which would be either recycled offsite as scrap metal or sent to a local landfill, would consist of: 1) stainless steel items such as the PLT vacuum vessel, vacuum pump lines, and other structures (total weight of 77 tons); 2) the PLT machine center column (total weight of 5 tons of A286 metal); 3) 8 tons of copper poloidal field (PF) coils; 4) 2 tons of insulating compound; and 5) 1 ton of epoxy. The NSTX tokamak would consist of four main demountable and upgradable components (Figures 2-1 and 2-2):

1. A stainless steel vacuum chamber composed of an upper dome, a lower dome (the two halves of the existing S-1 spheromak vacuum chamber), and a middle cylindrical chamber. The vacuum chamber would be about $11 \mathrm{ft}$ wide by $12 \mathrm{ft} \mathrm{high} \mathrm{with} \mathrm{a} 0.5$ inch thick wall. The inside of the vacuum chamber would be lined with carbon graphite tiles to protect the vessel walls from the plasma's heat. 
2. The coil structures consisting of: 12 outer TF coils (each consisting of 9 copper conductors) which would connect to the center stack (see 3 below) and would provide the main confining magnetic field; and the 6 outer PF coils, already attached to the existing S-1 upper and lower domes, to provide plasma shaping and stability.

3. A center stack running axially through the vacuum chamber, which would provide 4 ohmic plasma heating $(\mathrm{OH})$ coils, 4 inner PF coils, and 108 inner TF coil elements.

4. The supporting structure (existing PLT base) which would support various static and dynamic forces (e.g., the weight of NSTX, electromagnetic forces, thermal forces, etc.).

The NSTX would also require auxiliary systems including a vacuum/gas delivery system, coil power supply subsystem, heating and cooling subsystem, plasma diagnostics, data acquisition and control equipment, and plasma heating and current drive subsystem. The vacuum system would consist of roughing pumps, turbomolecular pumps, valves, vacuum hardware, and controls to provide the vacuum conditions necessary to create and sustain plasmas in NSTX. The motor generators and $\mathrm{PF} / \mathrm{OH}$ coil rectifier supplies currently used by the existing Princeton Beta Experiment - Modified (PBX-M) device would be shared by NSTX to power the coil systems necessary to confine and shape plasmas. A heating/cooling system would provide cooling for the vacuum chamber during operations, and heating to "bakeout" impurities from the vacuum chamber to allow achievement of low vacuum conditions. Plasma diagnostics, possibly utilizing some equipment from the Tokamak Fusion Test Reactor (TFTR), would provide signals which the data acquisition system would process to provide data on the performance of NSTX plasmas. The data acquisition/control system would also provide safety interlocking of all necessary devices (e.g., to ensure that personnel are not endangered by exposure to high voltages or excessive radiation during operations), and control of electrical, hydraulic and pneumatic inputs and outputs. Plasma heating and current drive capability would be provided by radio frequency heating, neutral beam injection, and helicity injection systems using mainly equipment already existing at PPPL.

Constructing the NSTX device in the existing PLT test cell area would allow use of the following existing resources in addition to those already mentioned: concrete radiation shield walls (which would provide shielding for neutron and gamma radiation generated during D-D plasma operation); overhead crane; deionized water supply and plumbing for component cooling; electrical power; and bus bars to supply power to the field coils.

\subsubsection{NSTX Operation}

Design, fabrication and assembly of NSTX would occur in fiscal years (FY) 96-98, with initial operations ("first plasma") scheduled for mid-1999 (see Figure 2-3). NSTX operations would be conducted over approximately a 10-year period. Initial experiments would be conducted with helicity injection for start-up and current profile control, and 
radio frequency heating for plasma auxiliary heating and current drive. NSTX could later be upgraded with a neutral beam injection system for additional plasma heating capability. Plasma pulse lengths would range up to 5 seconds in duration. Later upgrades could include operation at plasma currents up to $2 \mathrm{MA}$ and pulse lengths up to $60 \mathrm{sec}$. NSTX plasma operations would be conducted using hydrogen, deuterium, helium, and argon gases. These gases would be vented to the environment during machine operations to maintain vacuum conditions in the device. Liquid nitrogen and liquid helium would be used in cryogenic pumping systems to support neutral beam operations. Approximately 30,000 gallons/year of liquid helium and 70,000 gallons/year of liquid nitrogen would be used during NSTX neutral beam operations and vented as gases to the environment. NSTX would generate neutron and gamma radiation during plasma operations, but little or no detectable neutron activation of components or building air would be expected. During NSTX D-D experiments, less than 0.015 Curies per year of tritium gas would be produced and vented to the environment, and less than 0.001 Curies per year of tritium contamination in pump oil would be produced (Kugel 1993).

The NSTX program would be conducted at PPPL by a nationally based research team.

\subsubsection{Alternative To The Proposed Action}

The only alternative to the proposed action considered was the "no action" alternative, i.e., not dismantling PLT and not constructing NSTX for plasma research. This alternative would preclude efforts to investigate a promising alternative to the present approach to fusion which utilizes high aspect ratio tokamaks. While the NSTX or similar device could conceivably be constructed at another facility, the value of the PPPL "site credits" (estimated to be worth more than $\$ 50 \mathrm{M}$ vs. a total estimated project cost of about $\$ 18 \mathrm{M}$ ) would make this project much more costly than the proposed action, with no apparent programmatic or environmental benefits. Thus, this latter option was considered unreasonable and was therefore rejected.

\subsection{DESCRIPTION OF THE AFFECTED ENVIRONMENT}

The proposed NSTX would be located in the existing C-Stellarator (CS) Building at the CSite of PPPL (Figure 3-1). The NSTX would be housed in the four story high bay PLT Test Cell which has a floor space of 1,636 square feet. All activities associated with NSTX construction and operation would take place within the CS Building.

PPPL is located in central New Jersey approximately midway between Philadelphia and New York City. It is adjacent to U.S. Route 1, in the Township of Plainsboro. Additional information on the PPPL site and region can be found in DOE 1994. 


\subsection{ENVIRONMENTAL CONSEQUENCES OF THE PROPOSED ACTION AND ALTERNATIVE}

\subsection{Impacts of NSTX Construction}

As indicated in Section 2.1.1, some domestic waste would be generated during the dismantling of the existing PLT machine. This waste material would be sent to a local landfill, which would not be adversely impacted due to the small volume of waste compared to the capacity of the disposal facility. Much of the material removed during the dismantlement would be recycled for use on NSTX (along with material from the existing S-1 device), recycled offsite as scrap metal, or stored onsite for future use. Since all work would take place within the existing CS Building, there would be no impacts from NSTX construction on environmental resources such as air quality, noise, water quality and quantity, aquatic and terrestrial ecology (including threatened and endangered species), visual environment, land use, historical and archaeological resources, and socioeconomic environment.

Radiation doses to workers in the PLT Test Cell due to operation of the PBX-M device located next door (see Figure 2-2) may occur from exposure to direct and scattered gamma and neutron radiation, but would be controlled and maintained below the annual DOE standard of 5 rem effective dose equivalent (EDE), as well as the PPPL administrative limit of 1 rem per year. This would be accomplished and enforced with the use of administrative controls, monitoring, and precautionary measures (e.g., use of dosimeters within areas and on personnel; and evaluation, assessment, and preplanning of activities prior to entry to radiologically controlled areas and following radiological assessment by PPPL Health Physics). Based on past PBX-M operational experience, worker doses would not be expected to exceed 0.5 rem per year (Kugel 1993, Kugel 1995b). This occupational dose would result in an increased probability of health effects of less than 0.0002, based on the methodology used in DOE 1994.

All construction projects have the potential for worker injuries. Based on DOE averages, information in DOE 1994, and a projected construction labor effort of about 40 workeryears for PLT dismantlement and NSTX fabrication/assembly, over the NSTX construction period there would be an estimated 0.4 lost work cases (LWCs). LWCs are lost work days plus restricted work day cases. A lost work day is a day an employee is absent from work because of an injury at work. A restricted work day is a day an employee is present at work but restricted from normal activity because of an injury at work.

There would be no impacts from the no action alternative. 


\subsection{Impacts of NSTX Operation}

During NSTX operations, small amounts of hydrogen, deuterium, helium and argon gases used in plasma experiments, as well as vaporized liquid helium and liquid nitrogen used in the NSTX neutral beam injectors would be vented to the outside environment via a building vent. Venting of these types of gases has occurred during operation of PPPL's past and current experimental devices, and no adverse environmental impacts are anticipated from this operation.

The maximum estimated radiation dose to onsite personnel from neutron and gamma radiation generated during NSTX plasma operations would be less than 0.5 rem per year, based on PBX-M operating experience (Kugel 1993, Kugel 1995b). This occupational dose would result in an increased probability of health effects of less than 0.0002 . As indicated in Section 4.1, personnel exposures would be controlled to limit levels to less than the DOE and PPPL requirements of 5 rem per year and 1 rem per year, respectively.

The small amounts of tritium contaminated pump oil $(<0.001$ Curies per year) that would be produced during NSTX D-D operations would be disposed offsite as low level radioactive waste. It is assumed that such waste would be sent to the low level waste disposal facility at the DOE Hanford Site in Richland, Washington, as is current PPPL practice.

Offsite doses from direct and scattered radiation and tritium gas vented during NSTX operations would be very small $(<0.001$ rem per year, resulting in an increased probability of health effects of less than 0.0000005 to a member of the public), based on PBX-M operating experience (Finley and Wieczorek 1995) and analyses performed for the proposed Tokamak Physics Experiment, TPX (DOE 1994). No accident scenario has been identified that would cause a release of hazardous material from NSTX to the offsite environment.

Eventual dismantlement of NSTX following the end of experiments on this device may produce small amounts of low level radioactive wastes which would be sent to an offsite DOE disposal facility as indicated above for tritium contaminated pump oil produced during operations. Worker exposures during dismantlement would be limited to less than the PPPL requirement of 1 rem per year, and an increased probability of health effects of 0.0004 .

Unavoidable adverse impacts from the proposed action would include small radiation exposures to workers and the public, the potential for a small number of occupational injuries during PLT dismantlement and NSTX fabrication/assembly, and small quantities (relative to disposal capacity) of waste requiring disposal. Irreversible and irretrievable commitments of resources would include utility use (e.g., electricity, water), the beneficial expenditure of 40 worker-years during PLT dismantlement and NSTX fabrication/assembly, use of an estimated 300,000 gallons of liquid helium and 700,000 
gallons of liquid nitrogen over 10 years of NSTX operations, the use of some materials for NSTX fabrication/assembly which may not be fully recoverable, and land or space elsewhere for receiving waste generated during PLT dismantlement and NSTX construction, operation, and dismantlement. No adverse cumulative or long term impacts from the proposed action are anticipated based on PBX-M operating experience, the current absence of measurable cumulative impacts between PPPL and other facilities in the region, and the very low potential impacts from the proposed action.

There would be no impacts from the no action alternative. 


\subsection{REFERENCES}

DOE, 1994. Environmental Assessment, The Tokamak Fusion Test Reactor Decontamination and Decommissioning Project and the Tokamak Physics Experiment at the Princeton Plasma Physics Laboratory, DOE/EA-0813, U.S. Department of Energy, May 1994.

Finley, V. L. and M. A. Wieczorek, 1995. Princeton Plasma Physics Laboratory (PPPL) Annual Site Environmental Report for Calendar Year 1993, PPPL-3043, Princeton Plasma Physics Laboratory, January 1995.

Kugel, H. W., 1993. Memo to S. M. Kaye (PPPL). "PSTX Radiation." September 3, 1993.

Kugel, H. W., 1995a. Memo to J. Levine (PPPL). “NSTX EA.” May 15, 1995.

Kugel, H. W., 1995b. Memo to J. Levine (PPPL). "NSTX Long Pulse." May 15, 1995. 
U.S. Department of Energy

Finding of No Significant Impact

Proposed National Spherical Tokamak Experiment

Princeton Plasma Physics Laboratory, New Jersey

AGENCY: U.S. Department of Energy

ACTION: Finding of No Significant Impact

SUMMARY: The Department of Energy (DOE) has prepared an Environmental Assessment (EA), DOE/EA-1108, evaluating the environmental effects of the proposed construction and operation of the National Spherical Tokamak Experiment (NSTX) within the existing CStellarator (CS) Building at the Princeton Plasma Physics Laboratory, Princeton, New Jersey. The purpose of the NSTX is to investigate the physics of spherically shaped plasmas as an alternative path to conventional tokamaks for development of fusion energy. Fusion energy has the potential to help compensate for dwindling supplies of fossil fuels and the eventual depletion of fissionable uranium used in present-day nuclear reactors. Construction of the NSTX in the CS Building would require the dismantling and removal of the existing unused Princeton Large Torus (PLT) device, part of which would be reused to construct the NSTX.

Based on the analyses in the EA, the DOE has determined that the proposed action does not constitute a major federal action significantly affecting the quality of the human environment 
within the meaning of the National Environmental Policy Act (NEPA) of 1969, 42 U.S.C. 4321 et seq. The preparation of an Environmental Impact Statement is not required. Thus, the DOE is issuing a FONSI pursuant to the Council on Environmental Quality regulations implementing NEPA (40 CFR Parts 1500-1508) and the DOE NEPA implementing regulations (10 CFR Part 1021).

\section{DESCRIPTION OF THE PROPOSED ACTION:}

The proposed action consists of the construction and operation of the National Spherical Tokamak Experiment (NSTX) in the PLT Test Cell within the existing C-Stellarator (CS) Building at C-Site of PPPL. The NSTX would make use of existing parts, specifically, the upper and lower domes and the poloidal field coils of the existing non-operational S-1 spheromak. It would be located on the platform presently used for the non-operational PLT; thus, dismantlement and removal of the PLT device would be required. All existing parts that would be used to assemble the NSTX, as well as the waste resulting from dismantling and removal of the PLT, would be nonradioactive.

The NSTX experimental program would be conducted at PPPL by a nationally based research team. Its mission is to investigate the physics of spherical tokamak plasmas with low aspect ratios (i.e., ratio of major plasma radius to minor plasma radius) at dimensions and performance levels larger than those previously studied on smaller scale devices. This concept has the potential to simplify the application of the tokamak approach for fusion power production and as a volume neutron source. 
The PLT equipment removed to make way for assembly of NSTX would either be stored onsite at a different location, recycled offsite as scrap metal, or disposed offsite. About 93 tons of material would be recycled or disposed offsite. Constructing the NSTX device in the existing PLT Test Cell would allow use of the following existing resources: PLT platform (on which the device would be assembled), concrete radiation shield walls, overhead crane, deionized water supply and plumbing for component cooling, electrical power, and bus bars to supply power to the field coils. The NSTX would also share the existing motor generators and coil rectifier power supplies used by the existing Princeton Beta Experiment - Modified (PBX-M) device to power the coil systems necessary to confine and shape plasmas.

Design, fabrication and assembly of NSTX would occur in fiscal years (FY) 96-98, with operations conducted over approximately a 10-year period beginning in mid-1999. The cost for construction of NSTX is estimated at about $\$ 18 \mathrm{M}$. The fusion reactions that would occur in the NSTX tokamak involve various combinations of hydrogen $(\mathrm{H})$ and deuterium (D) (i.e., H-D and D-D reactions). Plasma current and pulse lengths would range up to 1 MegaAmpere (MA) and 5 seconds in duration, respectively. Later upgrades could include operation at plasma currents up to $2 \mathrm{MA}$ and pulse lengths up to 60 seconds.

\section{ALTERNATIVES:}

Two alternatives were considered: (1) the proposed action, dismantling of PLT to allow for construction and operation of the NSTX at PPPL, and (2) no action. The no action alternative would preclude efforts to investigate a promising alternative to the present 
approach to fusion which utilizes high aspect ratio tokamaks. There would be no environmental impacts from the no action alternative.

\section{ENVIRONMENTAL IMPACTS:}

The impacts of the construction and operation of the NSTX on the environment were analyzed in the Environmental Assessment. The Environmental Assessment considered impacts to air quality, noise, water quality and quantity, aquatic and terrestrial ecology, threatened and endangered species, visual environment, land use, historical and archaeological resources, socioeconomic environment, radiological conditions, and impacts of potential accidents. No significant environmental impacts associated with the proposed action are anticipated.

Radiation exposures to personnel in the PLT Test Cell during PLT dismantlement and NSTX assembly from operation of the PBX-M device located in an adjacent cell would not be expected to exceed 0.5 rem per year. This occupational dose would result in an increased probability of health effects of less than 2 chances in 10,000. For a construction project of this scope, the potential exists for 0.4 lost work cases (work related injuries requiring timeoff from work or restrictions from normal work activity) over the construction period. Waste material generated during dismantling of the PLT machine would be sent to a local landfill, which would not be adversely impacted due to the small volume of waste compared to the capacity of the disposal facility. 
Releases of nonradioactive plasma exhaust and cryogenic boiloff gases to the environment during NSTX operation would be of similar nature to those that have occurred during operation of PPPL's past and current experimental devices. No adverse environmental impacts from this operation are anticipated. Less than 0.015 Curies per year of tritium may be produced and vented to the environment during NSTX D-D operation. The annual effective dose equivalent to a hypothetical maximally exposed individual at the site boundary from this released tritium plus direct and scattered radiation produced during NSTX D-D operations would be less than 0.001 rem per year, resulting in an increased probability of health effects of less than 5 chances in 10,000,000 to a member of the public. Potential occupational exposures during NSTX operation would be essentially the same as during NSTX construction. No accident scenario has been identified that would cause a release of hazardous material from NSTX to the offsite environment. Tritium contaminated pump oil wastes (less than 0.001 Curies per year), and waste material resulting from eventual dismantlement of NSTX following the end of its operation would be expected to qualify as low level radioactive waste and would be disposed of at an appropriate DOE waste disposal facility.

\section{CUMULATIVE AND LONG TERM IMPACTS:}

No adverse cumulative or long term impacts from the proposed action are anticipated based on PBX-M operating experience, the current absence of measurable cumulative impacts between PPPL and other facilities in the region, and the very low potential impacts from the proposed action. 


\section{DETERMINATION:}

Based on the analyses in the Environmental Assessment, the DOE has determined that the proposed action at the PPPL is not a major Federal action significantly affecting the quality of the human environment within the meaning of the NEPA, consequently, an environmental impact statement is not required.

PUBLIC AVALABILITY: Copies of this EA (DOE/EA-1108) are available from:

Milton D. Johnson, Manager

Princeton Area Office, U.S. Department of Energy

P.O. Box 102

Princeton, New Jersey 08542

(609) 243-3700

For further information regarding the DOE NEPA review process, contact:

Dr. W. S. White

U.S. Department of Energy

9800 South Cass Avenue

Argonne, Illinois 60439

(708) 252-2101

Issued in Argonne, Illinois., this day of December, 1995.

Cherri J. Langenfeld

Manager

Chicago Operations Office 